\title{
Stevens-Johnson syndrome: relation with phenytoin and carbamazepine associated with HLA and CYP polymorphism in Colombia
}

\begin{abstract}
The genetic polymorphisms of the Human Leukocyte Antigens (HLA) and Cytochromes P450 (CYP) CYP2C19 and CYP2C9 have been proposed as key elements for susceptibility to antiepileptic drugs such as Phenytoin (PHT) and Carbamazepine (CBZ). These hepatic isoenzymes and HLA's exhibit genetic polymorphism with interindividual variability in catalytic activity. Stevens-Johnson Syndrome (SJS) is one of the idiosyncratic adverse effects related to PHT and CBZ. The aim of this work is to relate the polymorphisms of the HLA and CYP alleles with the Stevens- Johnson syndrome caused by phenytoin and carbamazepine in the Amerindian population of Colombia.
\end{abstract}

Methodology: A systematic search was carried out in Clinical Key, Pro Quest and PubMed, the results were tabulated and organized according to their expression to be analyzed by means of the MEGA7 software, using Allele Frequencies to know the allelic frequency of HLA in the Colombian Amerindian population.

Results: It was found that the increased risk of Stevens- Johnson syndrome by Phenytoin and Carbamazepine was significantly linked with HLA-A*23: 01, HLA-A*30: 01, HLA-A*30: 02, HLA-A*03:01, HLA-A*11: 01, HLA-A*26: 01, HLA-A*29: 02, HLA-A*68: 01, HLA-A*02: 01, HLA-A*02:22 relating HLA-B*15: 02 and HLA-B*51: 01 as a risk factor and HLA-A*24: 02 as a protective marker for SJS. In the population studied in this work, the presence of the alleles HLA-A*23:01, HLA-A*30:01, HLA-A*30:02, HLA-A*03:01, HLA-A*11:01, HLA-A*26:01, HLA-A*29:02, HLA-A*68:01, HLA-A*02:01, HLA-A*02:22, HLA-B*15:02 and HLA-A*24:02, like CYP2C9*3 and CYP2C19.

Keywords: carbamazepine, CYP, HLA, phenytoin
Volume 9 Issue 3 - 202I

\author{
Carlos Parga-Lozano, ${ }^{1,2}$ Nohemí \\ Santodomingo 1,2 \\ 'GIBIOM, Universidad Libre, Colombia \\ ${ }^{2}$ Innovation and Research Center Salud-CIIS, Salud Social IPS, \\ Colombia
}

Correspondence: Prof. Dr. Carlos Parga-Lozano, Department of Basic Sciences, Medicine Program, Libre University, Km7 Vía Puerto Colombia, Barranquilla, Colombia, Tel +57 3 I47548085 Email pargacarlos@yahoo.com

Received: May 19,202I | Published: June II, 2021

\section{Introduction}

The efficacy and safety of pharmacological therapy depends on the peculiarities of absorption, distribution, metabolism and excretion of drugs. ${ }^{1,2}$ The genetic polymorphisms of Human Leukocyte Antigens (HLA) and Cytochromes P450 (CYP) have been proposed as key elements for drug susceptibility. The cytochromes P450 CYP2C19, CYP2C9, CYP2D6, CYP2B6, CYP3A4 and CYP3A5 are essential for the susceptibility to antiepileptic drugs (AEDs) used clinically such as Phenytoin (PHT) and Carbamazepine (CBZ); these hepatic isoenzymes exhibit genetic polymorphism with interindividual variability in catalytic activity. The metabolism of drugs is mainly determined by the effect of the enzymes of the group of CYP. ${ }^{3-6}$

Epilepsy is one of the most prevalent neurological disorders worldwide, affecting approximately 70 million people in the world and at least 5 million of them are in Latin America. The general prevalence of epilepsy in Colombia is 11.3 per 1,000. No significant differences were found between the regions, except in the east, where the prevalence is higher. The prevalence rate of active epilepsy is 10.1 per 1,000 . Despite numerous attempts to develop safe and safe antiepileptic drugs, the occurrence of adverse effects is inevitable; Because they have different mechanisms of action, they can cause undesirable effects, whether neurological, psychiatric and affections of different organs and systems. ${ }^{7,8}$ The SJS has a global incidence of two cases per million inhabitants, with a significant social impact due to a mortality rate of $20-25 \%$, prolonged disability and rejection by the survivors of the use of medications. . $^{911}$

Adverse effects of antiepileptic drugs are classified into idiosyncratic adverse effects, adverse effects related to pharmacology and biological effect after modifying seizure frequencies. StevensJohnson Syndrome (SJS) is one of the idiosyncratic adverse effects related to PHT and CBZ.Stevens-Johnson syndrome (SJS) is a rare and life-threatening adverse skin reaction that is often triggered by certain medications including certain antiepileptic drugs. ${ }^{12,13}$ Several studies in the American continent have reported that among the antiepileptic drugs with SJS reactions, Carbamazepine stands out with a percentage of $11.1 \%$ and Phenytoin $7.1 \%$ in more than two thousand patients studied. It has been reported that within the etiological factors of SJS, in $67 \%$ there is a higher incidence with the use of anticonvulsant occupied in $55 \%$ by Carbamazepine and Phenytoin. ${ }^{14}$

In Colombia, the District Pharmacovigilance Program of the Secretary of Health of Bogotá reported that between 2008 and 2015 the aforementioned drugs accounted for $44.55 \%$ of adverse drug reactions in which Stevens Johnson syndrome was included, indicating that $17 \%$ of these were given by Carbamazepine. ${ }^{15}$

Phenytoin and Carbamazepine are one of the pillars of treatment for epileptic-convulsive status. ${ }^{16-18}$ The dosage is complex due to its highly unusual pharmacokinetics and whichrequires adjustments that can be made in line with the weight, sex and age of the patient. The 
initial dose should be lower in the context of liver failure. Side effects related to acute doses include sedation, ataxia, dizziness, nystagmus, nausea, and cognitive impairment. These drugs are highly allergenic, produce skin rashes ranging from mild rashes to life-threatening hypersensitivity reactions. Certain HLA class I alleles are associated with the SJS induced by Phenytoin and Carbamazepine. ${ }^{17-20}$

\section{Methodology}

A systematic search was performed in the PubMed and Elsevier databases with the following MeSH: $>>$ pharmacogenomics $<<,>>$ CYP/genetics $<<,>>$ HLA antigens/genetics $<<,>>$ Anticonvulsants/ adverse effects $<<, \quad>>$ Phenytoin/Adverse effects $<<, \quad>$ Carbamazepine/Adverse effects $<<,>>$ Stevens-Johnson syndrome/ chemically induced/genetic $<<$. Search filters were used to show only those studies called: Observational studies, meta-analyzes and/or systematic reviews. Product of the search in the PubMed database, 6 studies published between July 2008 and December 2018 made with humans were obtained. Of the 6,4 were observational and 2 were review type. We included observational or experimental studies that included patients with HLA and CYP polymorphisms using phenytoin and carbamazepine, designed to evaluate partial and complete remissions in response to treatment with these drugs. The bibliography of each selected study was reviewed in search of other relevant articles; In addition, additional information was searched in the Elsevier database with the topic of $>>$ Phenytoin-Carbamazepine/Adverse effects $<<$, $>$ Stevens Johnson syndrome $<<$. The epidemiological studies were obtained in the web portal of the same, using Allele Frequencies as a source of consultation to know the allelic frequency in the Amerindian population of Colombia.

\section{Results}

The association between genetic polymorphisms of HLA classes I and Cytochrome P450: CYP2C9*3 and CYP2C19 related to Phenytoin and Carbamazepine to Stevens-Johnson Syndrome (SJS) caused generally by adverse drug reactions in Thai and ChineseHan population was investigated (Figure 1). ${ }^{23-27}$ It was found that the alleles HLA-A*23: 01, HLA-A*30: 01, HLA-A*30: 02, HLA-A*03: 01, HLA-A*11: 01, HLA-A*26 : 01, HLA-A*29: 02, HLA-A*68: 01, HLA-A*02: 01, HLA-A*02: 22 relating HLA-B*15: 02 and HLA-B*51: 01 as a risk factor and HLA-A*24: 02 as a protective marker for SJS. The presence of the alleles HLA-A*23: 01, HLA-A*30: 01, HLA-A*30: 02, HLA-A*03: 01, HLA-A* was found in the population studied in this study. 11:01, HLA-A*26: 01, HLA-A*29: 02, HLA-A*68: 01, HLA-A*02: 01, HLA-A*02: 22, HLA-B*15: 02 and HLA-A*24: 02, as well as CYP2C9*3 and CYP2C19*2 (Table 2). ${ }^{28-42}$ There is an association between the alleles HLA-B*15: 02 and HLA-A*24: 02 and Stevens-Johnson Syndrome induced by Phenytoin and Carbamazepine in Asians, these alleles being presented characteristically in the Colombian population, so they should be studied as protective markers and genetic predisposition for this syndrome (Table 1 and Figure 2).
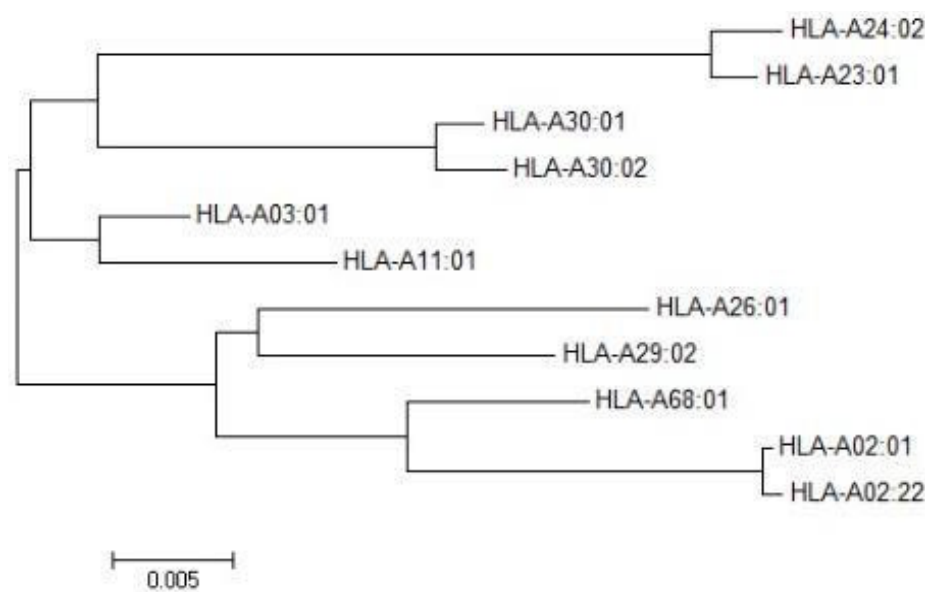

Figure I NJ analysis of the HLA alleles involved in the study.

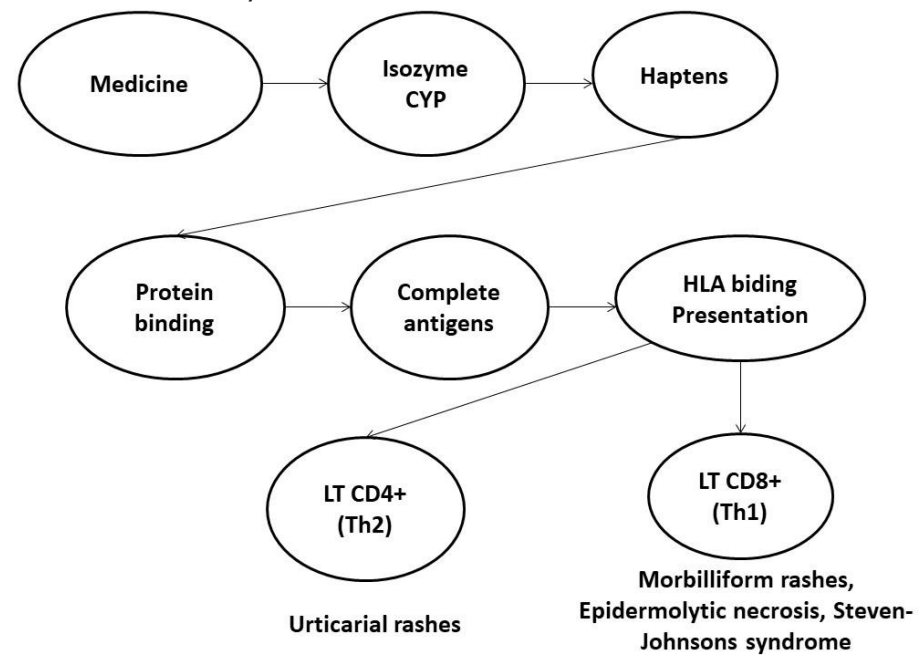

Figure 2 Mechanism of allergic drug reaction. 
Table I HLA allele frequencies in the studied Colombian population

\begin{tabular}{ll}
\hline Allele & Allelic Frequency (\%) \\
\hline HLA-A & \\
$* 02: 01$ & 16 \\
$* 02: 22$ & 9.6 \\
$* 03: 01$ & 21 \\
$* 11: 01$ & 14.7 \\
$* 23: 01$ & 11.9 \\
$* 24: 02$ & 45.7 \\
$* 26: 01$ & 9.1 \\
$* 29: 02$ & 22 \\
$* 30: 01$ & 8.3 \\
$* 30: 02$ & 11.3 \\
$* 68: 01$ & 10.6
\end{tabular}

Table 2 CYP allele frequencies in the world populations ${ }^{43}$

\begin{tabular}{lll}
\hline Alelle & Frequency $(\%)$ & Populations \\
\hline & 30.9 & Europeans \\
CYP2C9*3 & 5.8 & Africans \\
& 79.5 & East Asians \\
& 60.6 & South Asians \\
& 32.3 & Admixed Americans \\
& 44.7 & Europeans \\
& 32.6 & Africans \\
CYP2C19*2 & 78.5 & East Asians \\
& 70.7 & South Asians \\
& 43.9 & Admixed Americans \\
\hline
\end{tabular}

\section{Discussion}

There are several genes involved in metabolism and response to drugs; the most common are the genes of the Cytochrome P450 family (CYP), which encode enzymes that control the metabolism of more than $80 \%$ of prescription drugs. Patients who have variations in certain CYP genes often do not metabolize drugs to the same extent or extent as the average person. The existence of these genetic polymorphisms has several clinical implications. ${ }^{44}$ Four possible phenotypes have been determined based on the metabolizing activity of CYP2 enzymes: the Extensive Metabolizer (MS) is considered as a normal person since it processes the drugs in a timely and appropriate manner, Intermediate Metabolizer (IM) processes the drugs a little slower than an EM, a Poor Metabolizer (PM) that is not capable of processing drugs and a Ultra Rapid Metabolizer (UM) is a person who transforms drugs quickly. These polymorphisms are responsible for the adverse effects of drugs such as PHT and CBZ. Although the difference in the metabolic capacity of various drugs means that PMs have a higher risk of developing adverse effects to drug used at standard doses, unless there are alternative metabolic pathways. SJS is a disorder of the immune system that can be caused by drugs or medications; in some groups this pharmacological reaction may be aggravated by genetic factors such as the presence of alleles
HLA-A*23: 01, HLA-A*30: 01, HLA-A*30: 02, HLA-A*03: 01, HLA-A*11: 01, HLA-A*26: 01, HLA-A*29: 02, HLA-A*68: 01, HLA-A*02: 01, HLA-A*02: 22 (Table 1 and Figure 2) ${ }^{45-47}$

The Amerindian population descended from groups of huntergatherers of Siberian origin who migrated to America through the Bering Bridge, formed during a brief period of the last glaciation (Würm or Wisconsin), due to the decline in the level of the oceans. ${ }^{48}$

According to several theses of anthropology and archeology, the natives of America are from Asia. These thesis postulate that a branch of the Mongolian race crossed the Berring Strait and arrived in North America, then under Central and South America. They claim that the Asian and American continents were united 25,000 years ago in a period between 12,000 and 15,000 years ago. It is believed that there is kinship between American Indians and Eskimos. ${ }^{47-51}$ These HLA alleles have been found in the Thai and Chinese-Han populations associated with the Stevens-Johnson syndrome, the HLA-B*51: 01 allele was found with a ratio of $32.70 \%$ in the Amerindian population of Colombia, the presence of this Allele in the Amerindian population could be due to the different displacements of individuals from Asia to South America in the directions previously spoken thus showing a gene flow with the Asian population. ${ }^{52-54}$

Some patients who had the aforementioned HLA alleles suffered from SJS induced, but could be tolerant to other medications, so it is advisable to carry out previous studies of the allelic variants of HLA and CYP2 before administering these drugs to patients since CYP2C9*3 is typically associated with these two drugs. These HLA alleles are characteristically presented in the Amerindian population of Colombia, so it should be studied as a marker of genetic predisposition for SJS in Amerindians since certain HLA alleles in Amerindians show gene flow with Asians, Australians and inhabitants of the Pacific Ocean occurred in different times and in different directions (Table 1 and Figure 1). ${ }^{54}$

\section{Acknowledgments}

None.

\section{Conflicts of interest}

Authors declare that there is no conflict of interest.

\section{References}

1. Pozo Lauzán D, Pozo Alonso A. Antiepilépticos de tercera generación Third generation antiepilectics. Rev Cubana Pediatr. 2010;82(1):1-9.

2. Akk G, Shu H, Wang C, et al. Neurosteroid Access to the GABAA Receptor. J Neurosci. 2005;25(50):11605-11613.

3. De Leon J. Efectos de los inductores antiepilépticos en la neuropsicofarmacología: una cuestión ignorada. Parte II: cuestiones farmacológicas y comprensión adicional. Rev Psiquiatr Salud Ment. 2015;8(3):167-188.

4. Spina E, De leon J. Interacciones clínicamente relevantes entre los antidepresivos más nuevos y los antipsicóticos de segunda generación. Expert Opin Drug Metab Toxicol. 2014;10(5):721-746.

5. De Leon J, Santoro V, D'Arrigo C, et al. Interacciones entre antiepilépticos y antipsicóticos de segunda generación. Expert Opin Drug Metab Toxicol. 2012;8(3):311-334

6. Popovic I. A practitioner's guide to prescribing antiepileptics and mood stabilizers for adults with intellectual disabilities Springer New York Dodrecht Heidelberg London, 2012. Psychiatr Danub. 2012;24(4):405406. 
7. Vélez A. Epilepsia de difícil control. Asoc Colomb Neurol. 1998;123-135.

8. Ngugi A, Bottomley C, Kleinschmidt I, et al. Estimación de la carga de la epilepsia activa y de por vida: un enfoque metaanalítico. Epilepsia.2010;51(5):883-890.

9. Messenheimer J, Mockenhaupt M, Schlingmann J, et al. Riesgo de síndrome de Stevens-Johnson y necrólisis epidérmica tóxica en nuevos usuarios de antiepilépticos. Neurologia. 2005;64(7):1134-1138.

10. Mockenhaupt M, Viboud C, Dunant A, et al. Stevens-Johnson Syndrome and Toxic Epidermal Necrolysis : Assessment of Medication Risks with Emphasis on Recently Marketed Drugs. J Invest Dermatol. 2007;128(1):35-44

11. Torres M, Olmos E. Reacciones medicamentosas severas Síndrome Stevens Johnson y síndrome DRESS. Acta Médica Colomb. 2013;38(2):76-82.

12. Harr T, French L. Reacciones cutáneas adversas graves: pustulosis exantemática generalizada aguda, necrólisis epidérmica tóxica y síndrome de Stevens-Johnson. Med Clin North Am. 2010;94(4):727-742.

13. Auquier-Dunant, Mockenhaupt M, Naldi L, et al. Correlaciones entre patrones clínicos y causas de eritema multiforme majus, síndrome de Stevens-Johnson y necrólisis epidérmica tóxica: resultados de un estudio prospectivo internacional. Arch Dermatol. 2002;138(8):1019-1024.

14. Eric P Borrelli, Erica Y Lee, Andrew M Descoteaux, et al. StevensJohnson Syndrome and Toxic Epidermal Necrolysis with Antiepileptic Drugs: An Analysis of the Food and Drug Administration Adverse Event Reporting System. Epilepsia. 2018;59(12):2318-2324.

15. Andrea M García, Odair E Aldana Becerra. Caracterización de eventos adversos y problemas relacionados con Carbamazepina reportados al programa distrital de Farmacovigilancia Bogotá DC 2008-2015; 2016.

16. Mayor L. Tratamiento médico de la epilepsia. Asoc Colomb Neurol. 2011;1-14

17. Bergey GK. Future antiepileptic drug development. Neurology. 2000;55(5 Suppl 1):S47-53.

18. Blum D. Antiepileptic drug development: Advances in Neurology. Philadelphia Lippincott-Raven Publ. 1998;76:57-79.

19. Gonzales L, Del Pozo J, Herrero A, et al. Hepatotoxicidad asociada al tratamiento con fenitoina. Farm Hosp. 1995;27(10):307-309.

20. Silverman A, Fairley J, Wong R. Cutaneous and immunologic reactions to phenytoin. J Am Acad Dermatol. 1988;18(4):721-741.

21. Rapp R, Norton J, Young B, et al. Cutaneous reactions in head-injured patients receiving phenytoin for seizure prophylaxis. Neurosurgery. $1983 ; 13(3): 272-275$

22. Bohan K, Mansuri T, Wilson M. Anticonvulsant hypersensitivity syndrome: implications for pharmaceutical care. Pharmacotherapy. 2007;27(10):1425-1439.

23. Caudle K, Rettie A, Smith L, et al. Clinical Pharmacogenetics Implementation Consortium Guidelines for CYP2C9 and HLA-B Genotypes and Phenytoin Dosing. Clin Pharmacol Ther. 2014;96(5):542548.

24. Martin M, Klein T, Dong B, et al. Clinical Pharmacogenetics Implementation Consortium Guidelines for HLA-B Genotype and Abacavir Dosing. Clin Pharmacol Ther. 2012;91(4):734-738.

25. Leckband S, Kelsoe J, Dunnenberger H, et al. Clinical Pharmacogenetics Implementation Consortium Guidelines for HLA-B Genotype and Carbamazepine Dosing. Clin Pharmacol Ther. 2013;94(3):324-328.

26. Lee C, Goldstein J, Pieper J. Cytochrome P450 2C9 polymorphisms: a comprehensive review of the in-vitro and human data. Pharmacogenetics. 2002;12(3):251-263.

27. Hung S, Chung W, Liu Z, et al. Common risk allele in aromatic antiepilepticdrug induced Stevens-Johnson syndrome and toxic epidermal necrolysis in Han Chinese. Pharmacogenomics. 2010;11(3):349-356.
28. Mockenhaupt, M. Messenheimer J, Tennis P, et al. Riesgo de síndrome de Stevens- Johnson y necrólisis epidérmica tóxica en nuevos usuarios de antiepilépticos. Neurology. 2005;64(7):1134-1138.

29. Nassif A, Bensussan A, Boumsell L, et al. Toxic epidermal necrolysis : Effector cells are drug-specific cytotoxic T cells. J Allergy Clin Immunol. 2004;114(5):1209-1215.

30. Chung W, Hung S, Hong H, et al. Medical genetics: a marker for StevensJohnson syndrome. Nature. 2004;428(6982):486.

31. Cheung Y, Cheng S, Chan E, et al. HLA-B alleles associated with severe cutaneous reactions to antiepileptic drugs in Han Chinese. Epilepsia. 2013;54(7):1307-1314.

32. Chang C, Too C, Murad S, et al. Association of HLA-B*1502 allele with carbamazepine- induced toxic epidermal necrolysis and Stevens-Johnson syndrome in the multi-ethnicMalaysian population. Int $J$ Dermatol. 2011;50(2):221-224.

33. Hu F, Wu X, An D, et al. Phenytoin-induced Stevens-Johnson syndrome with negative HLA-B*1502 allele in mainland China : Two cases. Seizure. 2011;20(5):431-432.

34. Ikeda H, Takahashi Y, Yamazaki E, et al. HLA Class I markersin Japanese patients with carbamazepine-induced cutaneous adverse reactions. Epilepsia. 2010;51(2):297-300.

35. Kaniwa N, Saito Y, Aihara M, et al. HLA-B*1511 is a risk factor for carbamazepine-induced Stevens-Johnson syndrome and toxic epidermal necrolysis in Japanese patients. Epilepsia. 2010;51(12):2461-2465.

36. Ko T, Chung W, Wei C, et al. Shared and restricted T-cell receptor use is crucialfor carbamazepine-induced Stevens-Johnson syndrome. J Allergy Clin Immunol. 2011;128(6):1266-1276.e11.

37. Locharernkul C, Loplumlert J, Limotai C, et al. Carbamazepine and phenytoin induced Stevens-Johnson syndrome is associated with HLA- B * 1502 allele in Thai population. Epilepsia. 2008;49(12):2087-2091.

38. Man C, Kwan P, Baum L, et al. Association between HLA-B*1502 Allele and Antiepileptic Drug-Induced Cutaneous Reactions in Han Chinese. Epilepsia. 2007;48(5):1015-1018.

39. Mehta T, Prajapati L, Mittal B, et al. Association of HLA-B*1502 allele and carbamazepine-induced Stevens-Johnson syndrome among Indians. Indian J Dermatol Venereol Leprol. 2009;75(6):579-582.

40. Shi Y, Min F, Qin B, et al. Association between HLA and StevensJohnson Syndrome Induced by Carbamazepine in Southern Han Chinese Genetic Markers besides B*1502? Basic Clin Pharmacol Toxicol. 2012;111(1):58-64.

41. Tassaneeyakul W, Tiamkao S, Jantararoungtong T, et al. Association between HLA-B*1502 and carbamazepine-induced severe cutaneous adverse drug reactions in a Thai population. Epilepsia. 2010;51(5):926930.

42. Wang Q, Zhou J, Zhou L, et al. Association between HLA-B*1502 allele and carbamazepine-induced severe cutaneous adverse reactions in Han people of southern China mainland. Seizure. 2011;20(6):446-448.

43. Y Zhou, M Ingelman-Sundberg, VM Lauschke. Worldwide Distribution of Cytochrome P450 Alleles: A Meta-analysis of Population-scale Sequencing Projects. Clin Pharmacol Ther. 2017;102(4):688-700.

44. Alonso H, Jiménez F, García J. The role of CYP2C19 polymorphism in the development of adverse effects to drugs and the risk for diseases. Med Clin. 2006;126(18):697-706.

45. Isaza C, Sepúlveda J, Henao J. La farmacogenómica en medicina. Colomb Med. 2009;40(3):327-346.

46. Isaza $\mathrm{C}$, Henao J, Isaza J, et al. Phenotype-genotype analysis of CYP2C19 in Colombian mestizo individuals. BMC Clin Pharmacol. 2007;7:6.

47. Klotz U, Zimprich F, Schmidt D, et al. The clinical impact of pharmacogenetics on the treatment of epilepsy. Epilepsia. 2009;50(1):123 
48. Chou D. Los chinos en hispanoamerica. Fac Latinoam Ciencias Soc.

49. Silva O. Civilizaciones prehispanicas de America; 1985.

50. Sanchez L. América precolombina, descubrimiento y colonización; 1975.

51. Vargas G. Fusang: Chinos en America antes de Colon. Editorial Trillas; 1990.

52. Miroslava D, Tomasz G, Boris M, et al. Gene: Absence of Association with Papular Atrichia. Am J Hum Genet. 2001;69(1):235-237.
53. Williams R, Steinberg A, Gershowitz H, et al. GM allotypes in Native Americans: evidence for three distinct migrations across the Bering land bridge. Am J Phys Anthr. 1985;66(1):1-19.

54. Grover S, Kukreti R. HLA alleles and hypersensitivity to carbamazepine: an updated systematic review with meta-analysis. Pharmacogenet Genomics. 2014;24(2):94-112. 